\title{
Electrochemical Photocatalytic Degradation of Eriochrome Black T Dye Using Synthesized TiO $\mathbf{O}_{2}$ CNTs Nanofibers
}

\author{
Junren Zhu ${ }^{1, *}$, Zhenzhen Jiang ${ }^{2}$ \\ ${ }^{1}$ Chongqing City Management College, Chongqing 401331, P.R. China. \\ ${ }^{2}$ Chongqing Vocational Institute of Engineering, Chongqing402260, P.R. China. \\ *E-mail: zhujunren008@163.com
}

doi: $10.20964 / 2021.03 .55$

Received: 18 November 2020 / Accepted: 7 January 2021 / Published: 31 January 2021

\begin{abstract}
In this study, $\mathrm{TiO}_{2}$ and $\mathrm{TiO}_{2} @ \mathrm{CNTs}$ nanofibers were synthesized via electrospinning method and their morphological, structural, optical, electrochemical properties were considered. Furthermore, these electrodes were characterized as photocatalysts for degradation of Eriochrome Black T (EBT). The network rod structure of the porous electrospun $\mathrm{TiO}_{2}$ and $\mathrm{TiO}_{2} @ \mathrm{CNT}$ s nanofibers were observed. The high porous and large interfacial area of nanofiber of $\mathrm{TiO}_{2} @ \mathrm{CNT}$ s contained the uniform distribution and direct growth of $\mathrm{TiO}_{2}$ on the entangled bundles carboxylate MWCNT fibers surface. Optical study showed that the optical band gap values $3.19 \mathrm{eV}$ and $2.42 \mathrm{eV}$ were obtained for $\mathrm{TiO}_{2}$ and $\mathrm{TiO}_{2} @ \mathrm{CNTs}$ nanofibers, respectively which indicate preparing the hybrid system of homogeneous mixture of MWCNTs with $\mathrm{TiO}_{2}$ narrow the band gap and develops the visible light absorption. EIS result shows that the resistance for transfer of photo-generated electrons $\mathrm{TiO}_{2} @ \mathrm{CNTs}$ nanofibers samples were lower than $\mathrm{TiO}_{2}$. The high degradation efficiency of EBT on $\mathrm{TiO}_{2} @ \mathrm{CNT}$ nanofibers surface was obtained under visible irradiation because of the presence of MWCNTs which lead to narrow the band gap of hybrid system and promote the effective surface area and enhance the adsorption capacity of EBT on $\mathrm{TiO}_{2} @ \mathrm{CNT}$ snanofibers photo-catalyst surface. Moreover, recombination of photo-generated electronhole pairs can be decreased in $\mathrm{TiO}_{2} @ \mathrm{CNTs}$.
\end{abstract}

Keywords: Photocatalyst; Degradation efficiency; Eriochrome Black T; TiO ${ }_{2} @ \mathrm{CNT}$ s nanofibers; Photo-generated electron

\section{FULL TEXT}

2021 The Authors. Published by ESG (www.electrochemsci.org). This article is an open access article distributed under the terms and conditions of the Creative Commons Attribution license (http://creativecommons.org/licenses/by/4.0/). 